\title{
Bidirectional uncompressed HD video distribution over fiber employing VCSELs
}

\author{
Estaran Tolosa, Jose Manuel; Vegas Olmos, Juan José; Rodes, G. A.; Tafur Monroy, Idelfonso
}

Published in:

2012 IEEE Photonics Conference (IPC)

Link to article, DOI:

10.1109/IPCon.2012.6358473

Publication date:

2012

Link back to DTU Orbit

Citation (APA):

Estaran Tolosa, J. M., Vegas Olmos, J. J., Rodes, G. A., \& Tafur Monroy, I. (2012). Bidirectional uncompressed HD video distribution over fiber employing VCSELs. In 2012 IEEE Photonics Conference (IPC) (pp. 30-31). IEEE. https://doi.org/10.1109/IPCon.2012.6358473

\section{General rights}

Copyright and moral rights for the publications made accessible in the public portal are retained by the authors and/or other copyright owners and it is a condition of accessing publications that users recognise and abide by the legal requirements associated with these rights.

- Users may download and print one copy of any publication from the public portal for the purpose of private study or research.

- You may not further distribute the material or use it for any profit-making activity or commercial gain

- You may freely distribute the URL identifying the publication in the public portal 


\title{
Bidirectional uncompressed HD video distribution over fiber employing VCSELs
}

\author{
J. Estaran, J. J. Vegas Olmos, G. A. Rodes, I. Tafur Monroy \\ Department of Photonics Engineering \\ Technical University of Denmark (DTU) \\ DK2800 Kgs. Lyngby, Denmark \\ s101597@student.dtu.dk
}

\begin{abstract}
We report on a bidirectional system in which VCSELs are simultaneously modulated with two uncompressed HD video signals. The results show a large power budget and a negligible penalty over $10 \mathrm{~km}$ long transmission links.
\end{abstract}

\section{Keywords-high-definition (HD); VCSEL; bidirectional}

\section{INTRODUCTION}

Video distribution is one of the main drivers of the current bandwidth demand hike [1]. Video is usually transmitted employing network services [1], yet current demand of high definition (HD) channels and availability of ready-to-use HD receivers and transmitters lead to think that this distribution will be pushed down to the physical layer. Access networks are however very cost sensitive, and hence, cost-effective solutions for such distribution need to be engineered. Among the technologies that are clearly find a niche in this segment; vertical-cavity surface emitting lasers (VCSELs) are considered a viable solution to optical laser sources, because they provide a substantial operational bandwidth while having high integrability, low driving voltage and power dissipation requirements [2]. Figure 1 shows a network topology in which HD video signals are distributed directly over the physical layer.

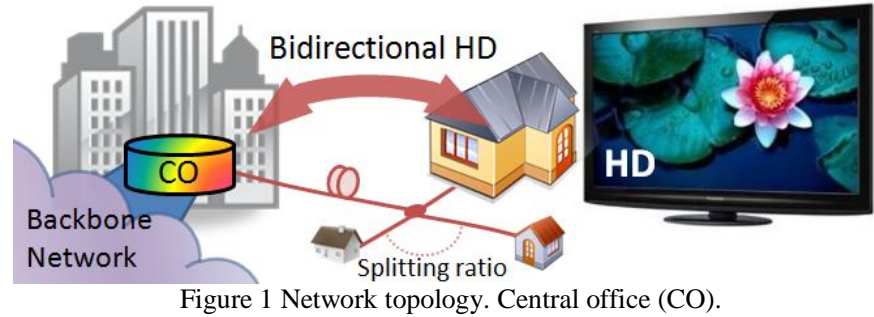

In this paper we present a two HD-channel bidirectional system employing low-driving voltage VCSELs operating at the Lband for the downstream and the O-band for the upstream. This band splitting prevents the system from crosstalk. The overall performance of the system demonstrates that VCSELs can be employed to simultaneously generate a plurality of uncompressed HD channels, enjoying a large power margin.

\section{EXPERIMENTAL SETUP}

Figure 3 shows the experimental setup and a superimposed picture of the transmitted optical spectrum. In order to emulate a high-definition serial digital interface (HD-SDI) and accounting for $7 \%$ margin for forward error correcting (FEC) coding implementation, we generated a $1.6 \mathrm{Gbps}$ with a $2^{15}-1$ pseudorandom bit sequence (PRBS) word length from a pulse pattern generator (PPG).The signal is divided into two through an active radio frequency (RF) splitter and decorrelated by using tunable electrical delay-lines. One of the branches is upconverted to $5 \mathrm{GHz}$ with an RF-mixer. The power of the local oscillator (LO) is tuned to optimize the eye diagram, and the mixer's insertion loss is compensated with an amplification stage. Baseband and the upconverted signals are added up with a 6-dB power combiner and subsequently amplified. The resulting signal is subdivided into two with another 6-dB electrical splitter and decorrelated via a mechanical delay line. The signals are adjusted to be around $1 \mathrm{Vpp}$ at the second power combiner's output.

The signals are used to modulate an L-band and an O-band VCSEL to generate the downstream and the upstream link, respectively. Both lasers exhibit $10 \mathrm{GHz} 3-\mathrm{dB}$ modulation bandwidth at ambience temperature and the unmodulated emitting center wavelengths are $1578.6 \mathrm{~nm}$ and $1281.9 \mathrm{~nm}-$ almost overlapping the 10G-EPON transmission bands. The output power was set to be $2 \mathrm{dBm}$ (downstream) and $-1.2 \mathrm{dBm}$ (upstream). O/C passive band splitters filters are used at each end of a $10 \mathrm{Km}$ long standard single-mode fiber (SSMF) spool for coupling and splitting the corresponding wavelengths.

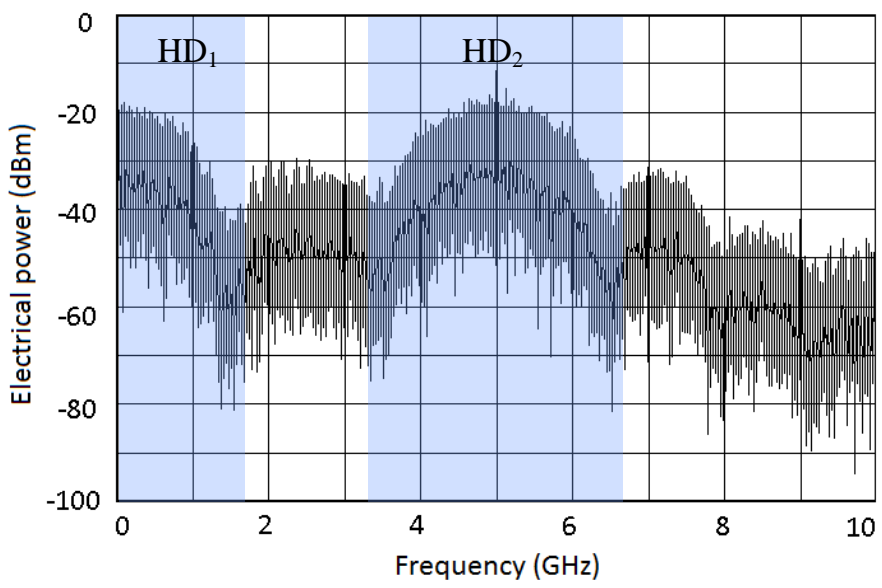

Figure 2 Transmitted electrical spectrum with $\mathrm{HD}_{1}$ and $\mathrm{HD}_{2}$ channels. 


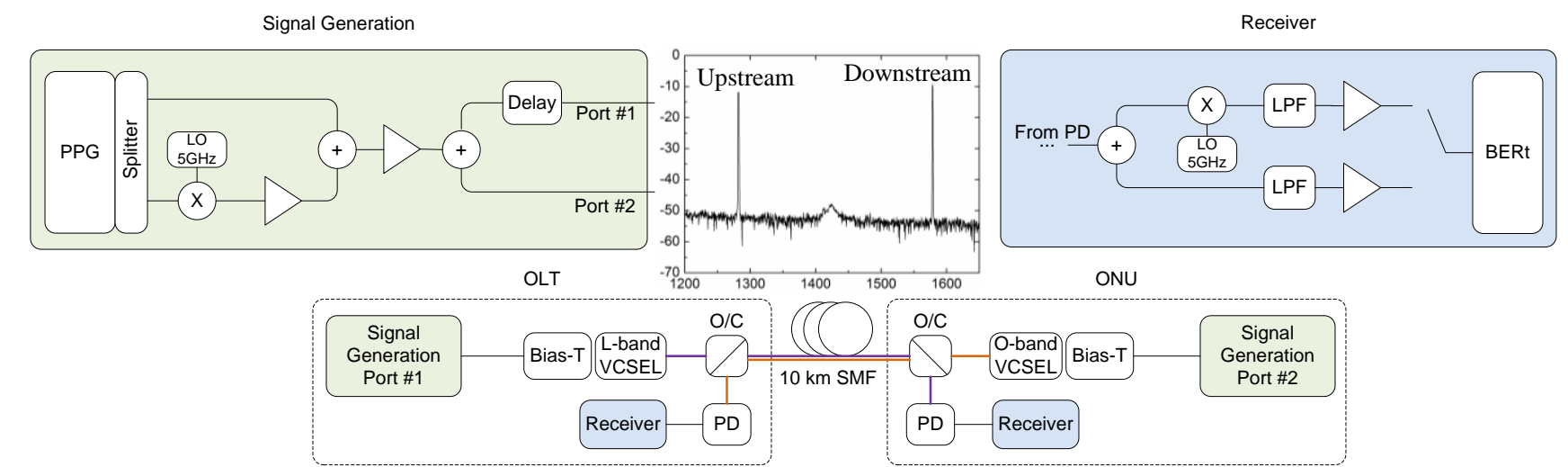

Figure 3 Experimental setup. Pulse pattern generator (PPG), local oscillator (LO), optical line termination (OLT), optical network unit (ONU), low-pass filter (LPF), photodiode (PD).

At the receiver side, a variable attenuator and a 20-dB coupler are used to control and monitor the incoming optical power. A high sensitivity 10-GHz PIN photodiode is used to detect the signal. After a passive electrical splitter, an RF-mixer is inserted in one of the branches for downconverting the $5 \mathrm{GHz}$ channel. An independent and synchronized LO is utilized. Low-pass filters with $1.8 \mathrm{GHz}$ cut-off frequency are used cancel off the harmonics and reduce the out-of-band (OOB) noise. Two individual low-noise high-linear amplification stages are applied after filtering. Finally, the outgoing stream is analyzed with a bit error rate (BER) tester.

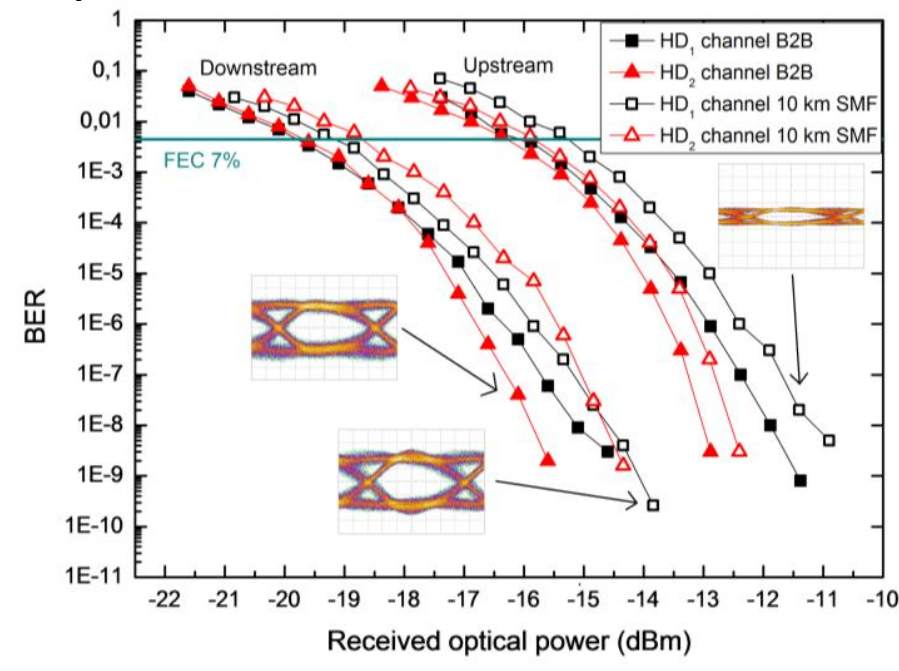

Figure 4 BER versus received optical power

At the receiver, a variable attenuator and a $20-\mathrm{dB}$ coupler are used to control and monitor the incoming optical power. A high sensitivity $10-\mathrm{GHz}$ PIN photodiode is used for sensing the signal. After a passive electrical splitter, an RF-mixer is inserted in one of the branches for downconverting the $5 \mathrm{GHz}$ channel. An independent and synchronized LO is utilized. The LO power had to be slightly adjusted to compensate for the band-dependent photodiode's responsivity. Low-pass filters with $1.8 \mathrm{GHz}$ cut-off frequency are used cancel off the harmonics and reduce the out-of-band (OOB) noise. Two individual low-noise high-linear amplification stages are applied after filtering. Finally, the outgoing stream is analyzed with a bit error rate (BER) tester.

\section{RESULTS AND DISCUSSION}

The BER curves for each optical source are shown in Figure 4. The O-band upstream performance shows a negligible average power penalty for both $\mathrm{HD} 1$ and HD2 of $0.5 \mathrm{~dB}$ with a maximum of around $1 \mathrm{~dB}$. The L-band downstream performance exhibits an indiscernible power penalty for both channels of less than $0.5 \mathrm{~dB}$. Concerning the transmission penalty, less than $0.5 \mathrm{~dB}$ is held in both lasers diodes for the two $\mathrm{HD}$ channels with the exception of the downstream $\mathrm{HD}_{2}$ case, for which a slightly increased deviation is observed. Figure 4 also shows some eye diagrams at different points.

No error floors are observed within the tested received power interval and the 7\%-FEC threshold is clearly exceeded for received power levels higher than $-16 \mathrm{dBm}$ for O-band and $19 \mathrm{dBm}$ for the L-band. This grants error free transmission $\left(\right.$ BER $10^{-15}$ ) under considerably relaxed power budget conditions. Such power margins allow a loss allocation (including transmission) of $15 \mathrm{~dB}$ and $21 \mathrm{~dB}$ in the upstream and downstream respectively, permitting diverse splitting ratio configurations (e.g. Class A optics in combination with $10 \mathrm{~km}$ link) and/or the consideration of additional safety margins.

\section{CONCLUSION}

Uncompressed HD video distribution needs to be addressed employing already deployed PON systems. We assessed how VCSELs can be used efficiently for such purpose and experimentally demonstrated two-channel bidirectional system over $10 \mathrm{~km}$ of SMF employing the L- and O-bands. During the presentation, we will show an interactive video describing the experimental setup and how HD video signals are recovered.

\section{REFERENCES}

[1] J. Joyce, "Bandwidth demand forecasting panel: compressed video forecasting," OFC'12, Harstead-Panel (2012).

[2] R. Rodes et al.,"100 Gb/s single VCSEL data transmission link," OFC'12, Postdeadline paper PDP5D.I0 (2012). 